PHYSICAL REVIEW D 95, 089901(E) (2017)

\title{
Publisher's Note: Testing strong-field gravity with tidal Love numbers [Phys. Rev. D 95, 084014 (2017)]
}

Vitor Cardoso, Edgardo Franzin, Andrea Maselli, Paolo Pani, and Guilherme Raposo

(Received 19 April 2017; published 27 April 2017)

DOI: 10.1103/PhysRevD.95.089901

This paper was published online on 10 April 2017 with incorrect text on page 17. On page 17, right-hand column, the original item (iv) has been removed and item (v) was subsequently renumbered to (iv) as of 19 April 2017. The text is not present in the printed version of the journal. 